in geology at the College; and the period spent by Rutherford at McGill University and the University of Manchester by Prof. D. C. H. Florance, who worked with Rutherford at Manchester at the time when the latter was formulating his theory of atomic structure. Dr. G. T. P. Tarrant, now senior lecturer in physics at Canterbury University College, but who formerly spent eight years at Cambridge, three as undergraduate and five as a research worker directly under Rutherford's guidance, contributes an appreciation of Rutherford and his work while at the Cavendish Laboratory, Cambridge. Dr. E. Marsden, who was associated with Rutherford both as student and colleague, and who has already paid tribute in Great Britain (Rutherford Memorial Lecture of the Physical Society, 1948) to Rutherford's kindness, amiability and greatness, gives an account of him as a man. The sixth address, by Prof. R. R. Nimmo, who recently returned to New Zealand after working for several years at the University of Birmingham on nuclear physics, describes the significance and importance of Rutherford's work in present-day nuclear research. This special issue of the Review, illustrated with several interesting photographs which have been made available by Lady Rutherford and which are published for the first time, is a fitting tribute to the great man's memory.

\section{Phytomorphology: a New Botanical Journal}

WITH the appearance of the first numbers of Phytomorphology, a. new botanical journal makes its appearance. This is the organ of the International Society of Plant Morphologists, founded at a meeting of the Pan-Indian Ocean-Science Congress held in Bangalore, India, in January of the current year. The object of the Society is to promote international co-operation in work on plant morphology, anatomy and embryology in the widest sense. It is hoped that the new journal will appear four times a year after the first year. Prof. P. Maheshwari, of the University of Delhi, is acting as convener of the Society and as editor (with the co-operation of botanists in different parts of the world) until formal elections to the executive council and editorial board can be held in 1952. Already some 290 members had been enrolled by October 1.

The first two numbers of vol. 1 of Phytomorphology make a substantial beginning. The papers include some of a specific factual kind and others in which themes of a more general character are discussed. Among the latter may be mentioned "The Use and Abuse of Anatomical Data in the Study of Phylogeny and Classification" (I. W. Bailey), "The Relationship of the Caytoniales" (T. M. Harris), "Organization in Plants" (C. W. Wardlaw), "The Male and Female Gametophytes of Angiosperms-An Interpretation" (E. Battaglia). A considerable paper on "The Leguminous Seed" is contributed by E. J. H. Corner, while A. G. Stokey has dealt in some detail with "The Contribution by the Gametophyte to Classification of the Homosporous Ferns". The journal is printed in a good clear type in double columns. The sub. scription is $£ 210 s$. a year.

Physics in Canada, 1951

A RECENT publication of the Canadian Association of Physicists, "Physics in Canada, 1951", contains several interesting articles and a valuable factual survey of research in physics in Canadian universities, research foundations and industrial and government laboratories, in addition to a directory of Canadian physicists. The preponderance of nuclear studies over other branches of physics is particularly striking. The director of the computation centre at the McLennan Laboratory of the University of Toronto, Dr. G. C. Gotlieb, in an article entitled "Machines for Thought", discusses the various types of computing machines and indicates their probable development and effects on scientific work. Turning to their effects on society, Dr. Gotlieb examines Wiener's ideas on the subject as stated in the latter's book, "The Human Use of Human Beings", and asserts that Wiener does not make it clear that the Industrial Revolution originates from a deeper source than the development of machines. Cosmic ray research in Canada is reviewed by Dr. D. C. Rose, of the National Research Council, Ottawa, and some trends in modern meteorology by Dr. D. P. McIntyre, of the Meteorological Division of the Department of Transport. "As I recall Rutherford" is the title of a brief article by Dr. C. H. Westcott, associate professor of physics at McGill University, and formerly of the University of Birmingham and the Telecommunications Research Establishment, England. Dr. Westcott, in his appreciation of Rutherford, recalls some of the impressions he gained when a research student at Cambridge in the Cavendish Laboratory during the last four years of Rutherford's directorship of the Laboratory.

\section{Publication of Papers by the Institution of Elec- trical Engineers}

A NOTEWORTHY modification in practice in regard to the publication of scientific papers by the Institution of Electrical Engineers was initiated with the issue in October of a new section, Part 4, of the Proceedings of the Institution. In this new Part will be published from time to time, and in any case not less often than once a year, papers which are considered to be of so specialized a character as to be essential to the work of only a small minority of the readers of Parts 1,2 and 3 of the Proceedings. The printing of such papers proceeds as soon as possible after their acceptance, and they are made available without delay as separate Institution monographs. The appearance of these is announced in the Journal of the Institution and on separate announcement sheets. A further step towards making Institution papers available as early as possible is the provision of early proofs of papers intended for presentation at a meeting of the Institution. Papers accepted for reading have first to take their place in the programme of meetings and may, after being read, have to wait possibly four or five months before being published. These papers are now printed without delay, and proofs are made available as soon as they are ready and are announced along with the monographs. There are, however, no early proofs of papers which have been accepted for publication but are not for reading at a meeting. The price of early proofs is $2 s .6 d$. and that of monographs $1 s$. $3 d$., but the earlyproof service provides, without further charge, a reprint of the paper together with the report of the discussion on it. To facilitate the purchasing of early proofs, reprints and' monographs, books of eight voucher-labels are available at a cost of $10 \mathrm{~s}$.

\section{Earthquake Activity in New Zealand during 1949}

THE Bulletin of the Dominion Seismological Observatory, Wellington, extracted from the annual report for 1950 of the New Zealand Department of Scientific and Industrial Research, states that in 1949 